\title{
Physico-Mechanical Properties of Cement-Bonded Particle Boards of Bambusa vulgaris and Gmelina arborea Fibres
}

\author{
D.N. Izekor ${ }^{*}$ and A.A. Erakhrumen \\ Department of Forest Resources and Wildlife Management, Faculty of Agriculture, University of Benin, \\ Benin City, Nigeria
}

Date Received: 03-01-2015 Date Accepted: 25-05-2015

\begin{abstract}
This study investigated the effect of pre-treatment and particle geometry/stratification on the physical and mechanical properties of cement-bonded particle boards (CBPBs). 6 mm thick homogeneous cement-bonded particle boards were made from Gmelina arborea roxb. sawdust and bambusa vulgaris shard. fibres with type 1 Portland cement. The CBPBs were manufactured at four particle geometry/stratification levels and three pre-treatment levels. The CBPB was manufactured with a cement wood ratio of $3: 1$, board density of $1500 \mathrm{~kg} / \mathrm{m}^{3}$, board size of $350 \times 350 \times 6 \mathrm{~mm}$ and a pressing pressure of $1.23 \mathrm{~N} / \mathrm{mm}^{2}$. The CBPBs were tested for modulus of rupture (MOR), modulus of elasticity (MOE), thickness swelling (TS) and water absorption (WA). The MOR obtained for each of the 12 factor combinations in this experiment ranged from 2.02 to $11.27 \mathrm{~N} / \mathrm{mm}^{2}$ while MOE value ranged from 253.88 to $4942.60 \mathrm{~N} / \mathrm{mm}^{2}$. The mean percentage for water absorption (WA) values ranged from $8.78 \%$ to $35.66 \%$ while mean TS values ranged from $0.16 \%$ to $15.71 \%$. Stronger and stiffer boards were produced using the sawdust/fibre/sawdust geometry stratification. Calcium chloride pre-treatment increased the mechanical properties of the boards, while $\mathrm{Al}_{2}\left(\mathrm{SO}_{4}\right)_{3}$ improved their physical properties. There were significant differences between particle geometry and pre-treatment on both physical and mechanical properties of cement-bonded particle board $(\mathrm{p}<0.05)$.
\end{abstract}

Keywords: fibre stratification, modulus of rupture, modulus of elasticity, thickness swelling, water absorption

\section{Introduction}

Fibre reinforcement of concrete remains an exciting and innovative technology because of its unique engineering properties. Presently, the major raw materials for cement-bonded particle boards consist mainly of wood, cement and water with or without a catalyst (Ajayi, 2005; Papadopoulos, 2008; Ajayi, 2011). The acceptability of these products stems from their availability and widespread distribution of local raw materials. The scarcity of the economically preferred wood species and overexploitation of natural and plantation hardwood species coupled with lack of effective utilisation of wood resources due to huge wastes by wood processing industries call for concerted efforts by researchers and wood scientists to initiate common solutions to the rapid depletion of wood resources in Nigeria. Finding alternative sources of raw materials for wood industries to manufacture panel

\footnotetext{
*Correspondence: david.izekor@uniben.edu
}

Tel: +23408039280692

ISSN 2235-9370 Print/ISSN 2235-9362 Online (C) University of Sri Jayewardenepura 
products would meet the ever increasing demand of wood products for construction works in Nigeria and the world in general.

The extraordinary mechanical performances of bamboo originate mainly from its fibre components (Amada and Untao, 2001). Bamboo fibres are much stronger and stiffer than most wood fibres, indicating that more attention should be focused on the utilisation of bamboo fibres in the production of high performance fibre reinforced composites (Yu et al., 2011a; 2011b). Bamboo and wood fibre composite are exceptional, not only because of their eco-friendly nature, but also because they provide an economic and socially useful outlet for bamboo chips, wood residues and agricultural wastes. The combination of bamboo and wood particles with the inorganic cement binder in the production of a cement bonded particle board (CBPB) can produce a new class of building products that will reflect the good characteristics of wood, non-wood and concrete.

Particle geometry influences virtually all properties of cement-bonded particle board (Frybort et al., 2008). Wood composite properties can be engineered to an extent, by adjusting the particle geometry and their arrangement. This implies that particle geometry affects the strength and physical properties of the composite and as such the mixture of different fibre particles and particle geometry in a layered arrangement of a multi-layered cement-bonded particle board (CBPB) should have a significant effect on the strength and physical properties of the product. The objective of this study is to determine the effects of different particle stratification and geometry on the physical and mechanical properties of cement-bonded plastic composites. The influences of particle layering and different pretreatment on the properties of the composites were also evaluated.

\section{Methodology}

The study was carried out at the Forest Product Development and Utilisation Department of Forestry Research Institute of Nigeria (FRIN), located at Jericho in Ibadan, the capital of Oyo State, Nigeria.

\subsection{Fibre acquisition}

Two components were involved in fibre acquisition. These were the non-wood component and the wood component. For the non-wood (bamboo fibre) component, fresh culms of Bambusa vulgaris were harvested and the nodes on the culms were removed and prepared into chips. The processed chips were then processed for fibre analysis. The second component involved the collection of Gmelina arborea sawdust from the sawmill section of the Forestry Research Institute of Nigeria. The sawdust was air-dried to a constant moisture content of $12 \%$ in a controlled laboratory and then processed for fibre/particle analysis.

\subsection{Fibre analysis}

Bambusa vulgaris

Maceration was done by soaking the chips in water for 48 hours and then gently beaten to release the fibres (Wise et al., 1946; Gills and Onuga, 1989). The fibre dimensions were thereafter measured and recorded.

\section{Gmelina arborea}

The dried sawdust was thoroughly sieved using $2.0 \mathrm{~mm}$ and $1.0 \mathrm{~mm}$ sieves while the geometry was obtained by passing the sawdust through the sieves. 


\subsection{Pre-treatment and treatment additives}

Both bamboo fibre and Gmelina wood sawdust were pre-treated with hot water in an aluminium hot bath at $100^{\circ} \mathrm{C}$ for a period of one hour. Thereafter, the water was drained off and the particles were dried to a moisture content of $12 \%$. Three treatment regimens were carried out for the four board types. The first was the control regime with no treatment followed by the calcium chloride $\left(\mathrm{CaCl}_{2}\right)$ additive and the aluminium sulphate $\left(\mathrm{Al}_{2}\left(\mathrm{SO}_{3}\right)_{4}\right)$ additive. For each mineralising chemical additives, $2 \%$ weight of cement was added to the cement-wood slurry.

\subsection{Sample preparation}

Six sample boards were produced for each particle geometry type and treated according to the cement-wood mixing ratio 3:1. From these sample boards, two test samples were cut out for physical and mechanical properties tests, using prescribed dimensions. A total of 12 test samples were used for each fibre geometry type. The wood particles and the cement for the board manufacture were weighed, recorded and labelled for identification.

The required quantity of wood particles and cement was weighed and placed in a plastic container. The solution of $2 \%$ calcium chloride and water was added in a uniform proportion and blended together to form slurry. This same procedure was done for other treatment regimens. Wooden moulds of known dimensions were placed on a wooden plate and covered with a polythene sheet to prevent sticking of the formed boards onto the plate. The slurry was now spread out on the plate in the wood mould, after which, a wood press was used to pre-press the furnish within the mould to enhance uniform mat formation and to reduce the thickness of the formed mat. The mat formed was properly labelled using a paper cello tape to distinguish between boards from different particle geometry and different treatment regimens. The labelled mat was covered with polythene sheet, thereafter a top metal plate was placed on it and transferred to the cold press under a pressing pressure to a specified thickness for a period of 24 hours before demoulding. Cold pressing was done using a hydraulic cold press machine. After pressing, the demoulded boards were stored inside sealed polythene bags for 28 days to enhance curing of the cement binder. The cured boards were trimmed to avoid edge effect and cut into test specimen sizes for testing. The boards were tested for modulus of rupture (MOR), modulus of elasticity (MOE), water absorption (WA) and thickness swelling (TS).

\subsection{Testing for physical properties}

Test samples measuring $50 \times 50 \mathrm{~mm}$ were used for physical properties determination according to British Standard 373 (1989). The properties tested were water absorption and thickness swelling. Measurements of thickness $(\mathrm{mm})$ and weight of the samples were taken prior to test as initial parameters while the final measurement was taken after immersion in distilled water for 24 hrs. Digital calliper and electronic weighing balance was used to measure thickness swelling and weight of the test samples. The different parameters were calculated using the equation.

\section{Water absorption}

$$
\begin{aligned}
& W A(\%)=\left(W 2-\frac{W 1}{W 1}\right) \times 100 \\
& \text { where: } \quad \begin{aligned}
\mathrm{WA} & =\text { Water Absorption }(\%) \\
\mathrm{W}_{2} & =\text { final weight after treatment }(\mathrm{g}) \\
\mathrm{W}_{1} & =\text { initial weight before treatment }(\mathrm{g})
\end{aligned}
\end{aligned}
$$


Thickness swelling

$$
\begin{aligned}
& T S(\%)=\left(T 2-\frac{T 1}{T 1}\right) \times 100 \\
& \text { where: } \begin{aligned}
\mathrm{TS}(\%)=\text { Thickness swelling in percentage } \\
\mathrm{T}_{2}=\text { final thickness after treatment }(\mathrm{mm}) \\
\mathrm{T}_{1}=\text { initial thickness before treatment }(\mathrm{mm})
\end{aligned}
\end{aligned}
$$

\section{Mechanical properties}

The modulus of rupture test was carried out using test samples measuring $50 \times 150 \mathrm{~mm}$ on a Hounsfield Tensiometer Machine according to British Standard 373 (1989). The test samples were supported by two rollers at both ends and loaded at the middle of the span until failure occurs. MOR was calculated from the maximum load at which each sample failed. Modulus of elasticity (MOE) was calculated using the load to deflection curve plotted on the graph by the Hounsfield Tensiometer testing machine as expressed in the equation below:

$$
\begin{aligned}
& \text { MOR }=\frac{3 P L}{2 b d^{2}} \\
& \text { where: } \quad \begin{aligned}
\text { MOR } & =\text { modulus of rupture }\left(\mathrm{Nmm}^{-2}\right) \\
\mathrm{P} & =\text { the ultimate failure load }(\mathrm{N}) \\
\mathrm{L} & =\text { the wood sample span between the machine support }(\mathrm{mm}) \\
\mathrm{b} & =\text { width of the wood sample }(\mathrm{mm}) \\
\mathrm{d} & =\text { thickness of the wood sample }(\mathrm{mm})
\end{aligned} \\
& \text { MOE }=\frac{\Delta P L^{3}}{4 b d^{3} \Delta s} \\
& \text { where: } \quad \begin{aligned}
\mathrm{MOE} & =\text { modulus of elasticity }\left(\mathrm{Nmm}^{-2}\right) \\
\mathrm{P} & =\text { increment in load }(\mathrm{N}) \\
\mathrm{L} & =\text { the span of the sample between the machine support (mm) } \\
\mathrm{b} & =\text { width of the sample }(\mathrm{mm}) \\
\mathrm{d} & =\text { thickness of the sample }(\mathrm{mm}) \\
\Delta \mathrm{s} & =\text { increment in deflection corresponding to increment in load. }
\end{aligned}
\end{aligned}
$$

Analysis of variance was carried at $0.05 \%$ probability level to estimate the level of significance among the various parameters tested while separation of means was carried out using Duncan Multiple Range Test.

\section{Results and Discussion}

\subsection{Physical Properties}

Water Absorption

The results of the mean values of cement-bonded particle boards (CBPBs) after 24 hours of water absorption (WA) with $\mathrm{CaCl}_{2}$ treatment after 24 hours are presented in Figures 1 and 2. The values were $11.75,8.78,25.89$ and $12.08 \%$ for sawdust-fibre-sawdust (S-F-S), fibre-sawdust-fibre (FS-F), sawdust only (S only), and fibre only (F only) particle geometry/stratification levels respectively. 
The mean values of CBPBs for water absorption treated with $\mathrm{Al}_{2}\left(\mathrm{SO}_{4}\right)_{3}$ were 11.84, 13.27, 12.00 and $13.93 \%$ for S-F-S, F-S-F, S only and F only particle geometry/stratification levels respectively while the mean values for CBPBs produced with no chemical treatment were 14.60, 27.44, 35.66 and 24.94 for S-F-S, F-S-F, S only and F only particle geometry/stratification levels respectively (Figures 1 and 2). Cement-bonded boards produced with additive chemical of $\mathrm{Al}_{2}\left(\mathrm{SO}_{4}\right)_{3}$ had a lower rate of water absorption compared to those produced with additive chemical of $\mathrm{CaCl}_{2}$ while cement-bonded board produced with no chemical treatment had the highest rate of water absorption. The high rate of water absorption observed in CBPBs treated with $\mathrm{CaCl}_{2}$ could be attributed to the hygroscopic nature of the chemical. This observation is similar to earlier report by Xu and Stark (2005). The authors reported that within each treatment, it was observed that boards produced with the S-F-S (sawdust/fibre/sawdust) matrix stratification were the most resistant to water absorption.

\section{Thickness swelling}

The results of thickness swelling percentage of cement-bonded particle boards are presented in Figures 1 and 2. The mean thickness swelling percentage of $\mathrm{CBPBs}$ treated with $\mathrm{CaCl}_{2}$ after 24 hours of water absorption were 2.66, 3.39, 0.95 and $1.13 \%$ for sawdust-fibre-sawdust (S-F-S), fibre-sawdustfibre (F-S-F), sawdust only ( $\mathrm{S}$ only), fibre only ( $\mathrm{F}$ only) particle geometry/stratification levels respectively. The mean thickness swelling percentage of CBPBs treated with $\mathrm{Al}_{2}\left(\mathrm{SO}_{4}\right)_{3}$ after 24 hours of water absorption were $0.83,1.37,0.16$ and $0.33 \%$ for S-F-S, F-S-F, S only and F only particle geometry/stratification levels respectively while the mean thickness swelling percentage for CBPBs produced with no chemical treatments were 1.44, 15.71, 2.30 and 5.58\% for S-F-S, F-S-F, S only and F only particle geometry/stratification levels respectively. Cement-bonded boards produced with the $\mathrm{Al}_{2}\left(\mathrm{SO}_{4}\right)_{3}$ treatment additives exhibited the least change in thickness swelling (Figure1). This was followed by boards produced with the $\mathrm{CaCl}_{2}$ and no treatment additive respectively. Within each treatment as shown in figure 3, boards produced with sawdust only exhibited the least mean thickness swelling values. This shows that boards produced with sawdust only were the most dimensionally stable in terms of thickness swelling, followed by boards produced with fibres only. The observation made on the mean thickness swelling of the treated boards ranged from $0.16 \%$ to $3.39 \%$ compared to the thickness swelling values of CBPBs with no chemical treatment which ranged from $1.44 \%$ to $15.71 \%$. This shows the effect of chemical treatment on thickness swelling. The thickness swelling percentages observed in this study compared favourably with ranges of $1.56 \%$ to $3.95 \%$ as previously reported by Morteza et al. (2011) on the influence of wood extractive and additives on the hydration kinetics of cement paste.

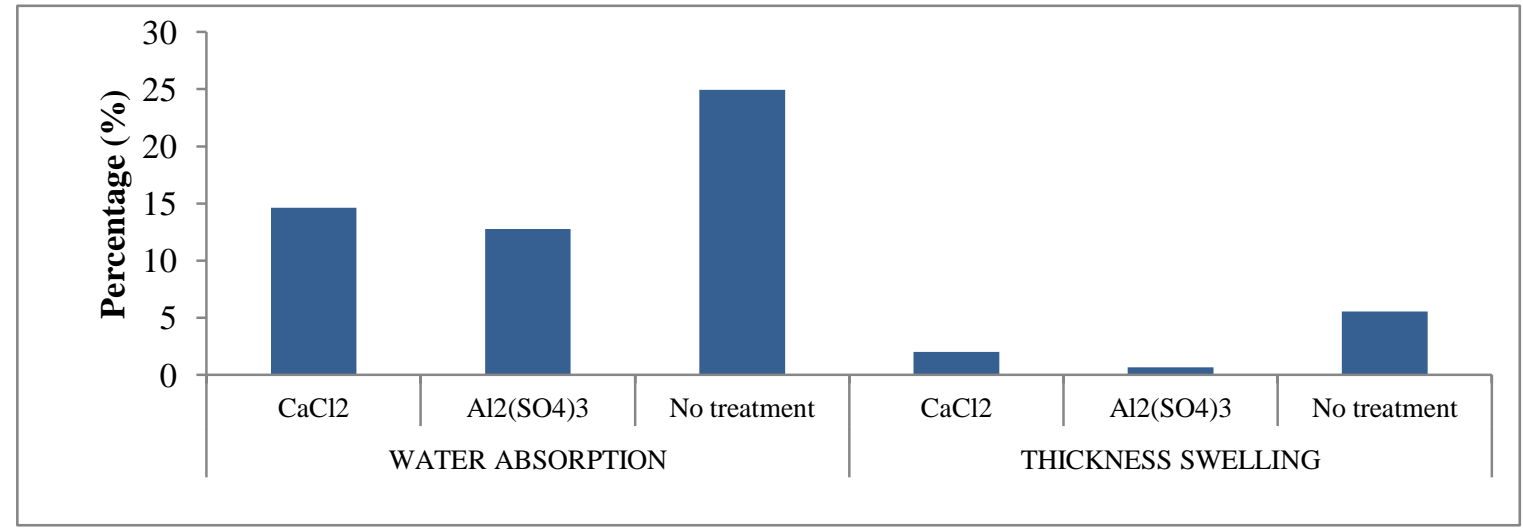

Figure 1: Effect of pre-treatment on water absorption and thickness swelling of CBPBs. 


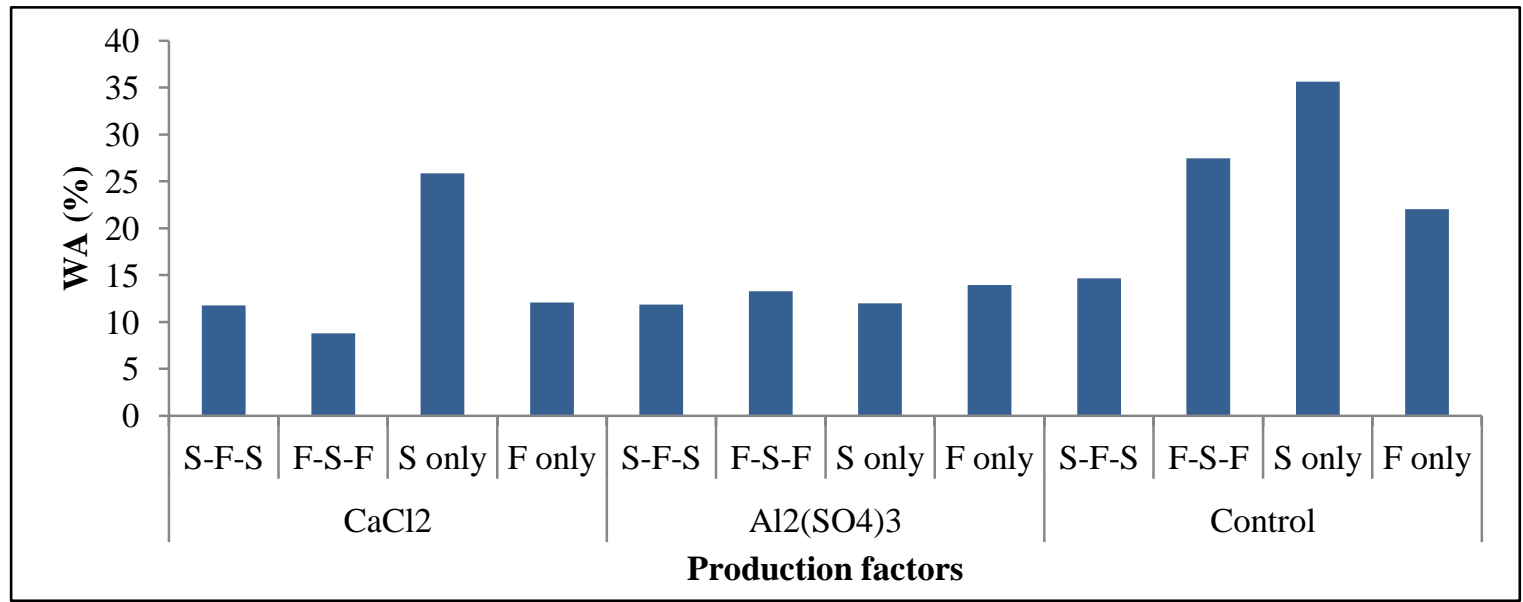

Figure 2: Effect of chemical treatments and fibre geometry on water absorption of cement-bonded particle boards.

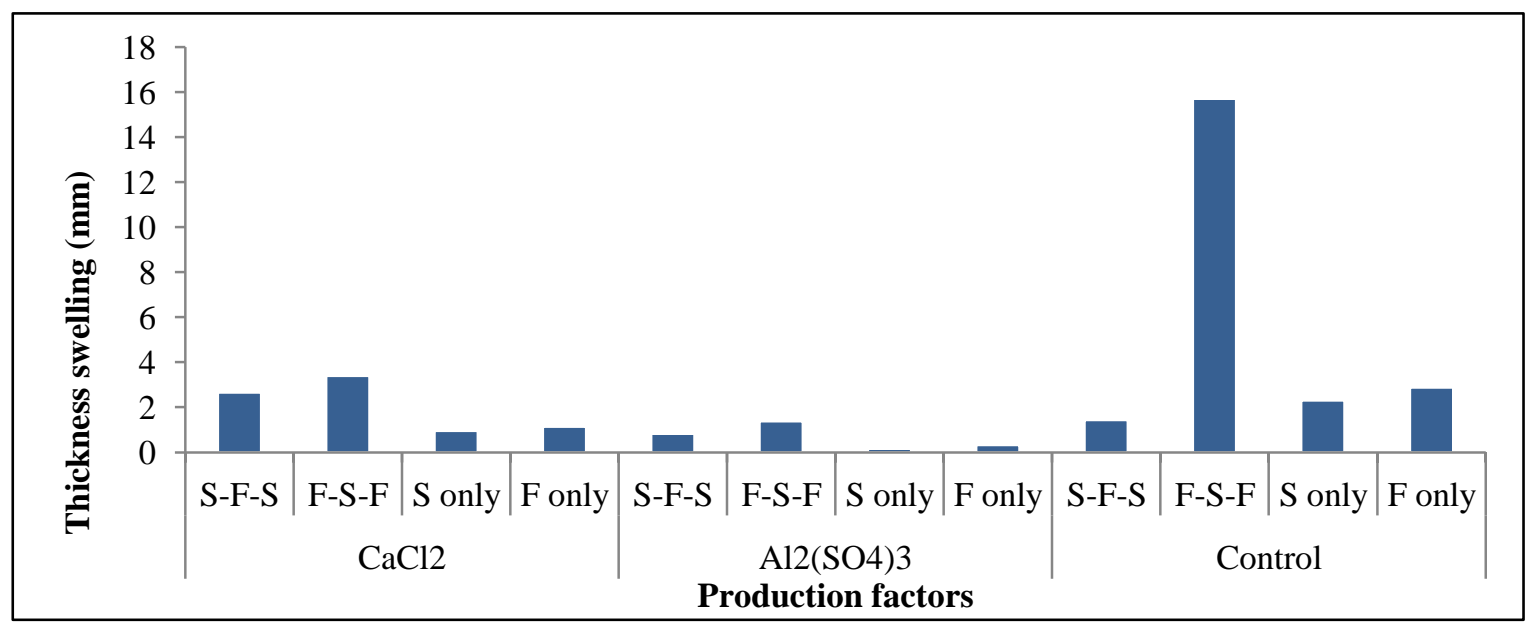

Figure 3: Effect of chemical treatments and fibre geometry/stratification on thickness swelling of cement-bonded particle boards.

\subsection{Mechanical Properties \\ Modulus of rupture}

The results of the mechanical properties of cement-bonded particle boards are presented in Figure 4. The mean values of MOR for $\mathrm{CBPBs}$ treated with $\mathrm{CaCl}_{2}$ were 11.27, 7.34, 6.34 and 10.20 $\mathrm{Nmm}^{-2}$ for sawdust-fibre-sawdust (S-F-S), fibre-sawdust-fibre (F-S-F), sawdust only (S only), fibre only (F only) particle geometry/stratification levels respectively. The mean values obtained for MOR for CBPBs treated with $\mathrm{Al}_{2}\left(\mathrm{SO}_{4}\right)_{3}$ were $6.27,3.43,3.86$ and $3.20 \mathrm{Nmm}^{-2}$ for S-F-S, F-S-F, S only and F only particle geometry/stratification levels respectively while the mean values obtained for CBPBs produced with no chemical pre-treatment were 3.35, 4.72, 5.21 and $2.02 \mathrm{Nmm}^{-2}$ for S-F-S, F-S-F, S only and $\mathrm{F}$ only particle geometry/stratification levels respectively. The effects of chemical pretreatment on the modulus of rupture of cement-bonded particle boards are presented in Figure 5. It was observed that $\mathrm{CaCl}_{2}$ treated boards has the highest MOR values, followed by boards treated with $\mathrm{Al}_{2}\left(\mathrm{SO}_{4}\right)_{3}$. CBPBs produced with no chemical pre-treatment have the lowest MOR values. Also CBPBs produced using different particle geometry had greater MOR values in the sawdust/fibre/sawdust stratification followed by fibre/sawdust/fibre stratification. 


\subsubsection{Modulus of elasticity}

The mean values of MOE obtained for CBPBs treated with $\mathrm{CaCl}_{2}$ pre-treatment were 3796.10, 3575.90, 2835.80 and $4942.60 \mathrm{Nmm}^{-2}$ for sawdust-fibre-sawdust (S-F-S), fibre-sawdust-fibre (F-S-F), sawdust only ( $\mathrm{S}$ only), fibre only (F only) particle geometry/stratification levels respectively. The mean MOE values obtained for boards with $\mathrm{Al}_{2}\left(\mathrm{SO}_{4}\right)_{3}$ pre-treatment were 1747.20, 745.52, 842.82 and $1472.60 \mathrm{Nmm}^{-2}$ for S-F-S, F-S-F, S only and F only particle geometry/stratification levels respectively. The mean MOE values obtained for CBPBs with no pre-treatment were 629.44, 1110.20, 1686.30 and $253.88 \mathrm{Nmm}^{-2}$ for S-F-S, F-S-F, S only and F only particle geometry/stratification levels respectively.

Figure 6 shows the effect of chemical pre-treatment and fibre geometry/stratification on the MOE of the CBPBs produced. It was observed that CBPBs pre-treated with $\mathrm{CaCl}_{2}$ had the highest values of $\mathrm{MOE}$ followed by boards produced with pre-treated $\mathrm{Al}_{2}\left(\mathrm{SO}_{4}\right)_{3}$ while boards with no treatments had the lowest MOE values. Comparing the overall means for each geometry/stratification of fibre, CBPBs produced using the sawdust/fibre/sawdust had the highest mean followed by CBPBs produced with fibres only. The lowest values of MOE were observed in cement-bonded boards produced with no treatment.

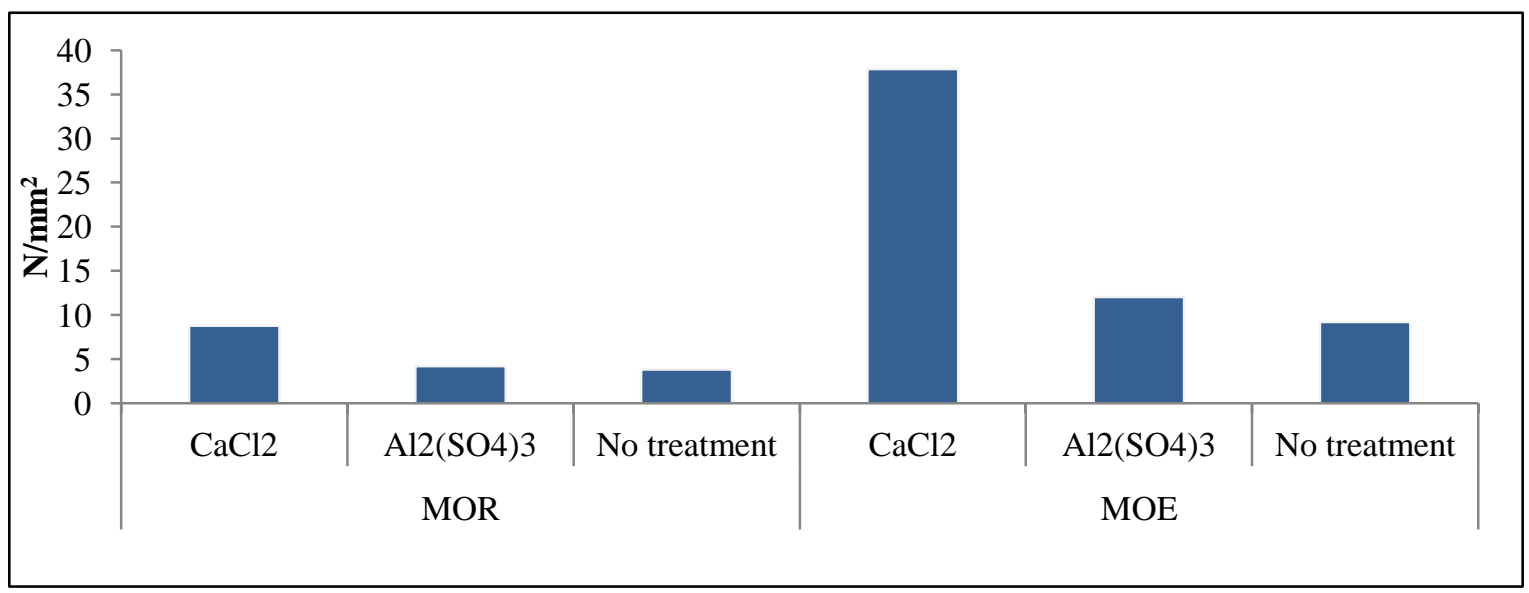

Figure 4: Effect of pre-treatment on MOR and MOE of cement-bonded particle boards.

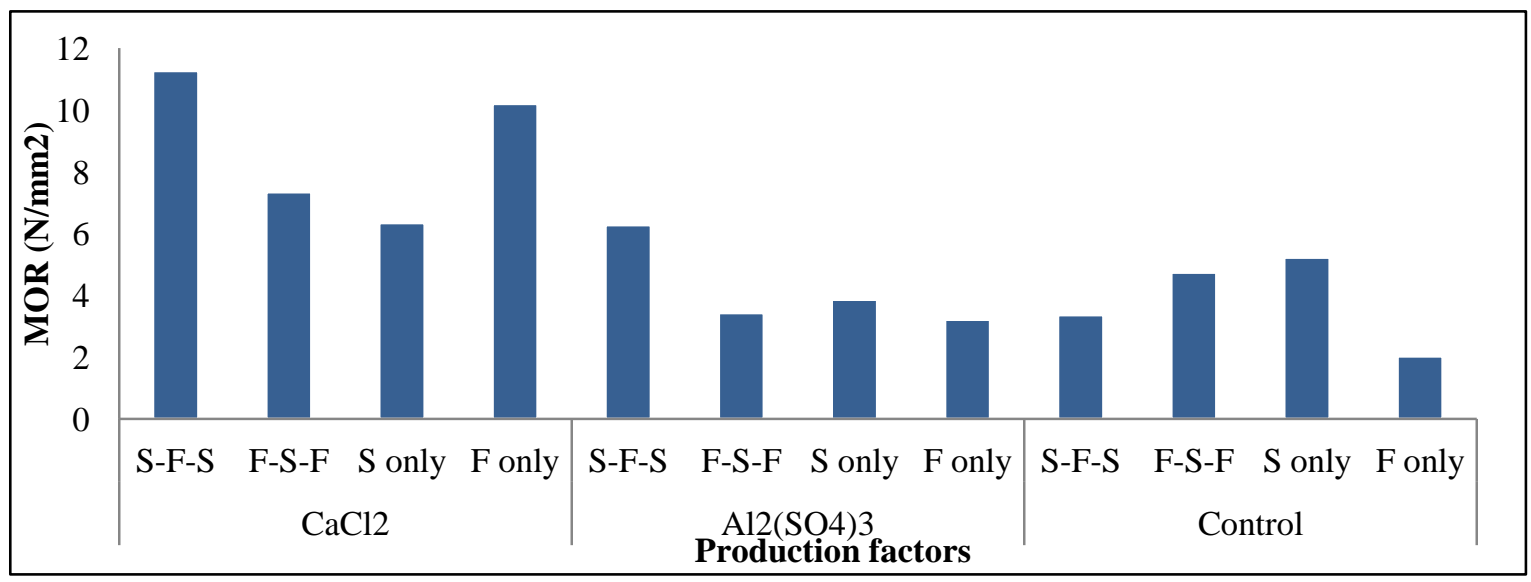

Figure 5: Effect of chemical treatments and fibre geometry on MOR of cement-bonded particle boards. 


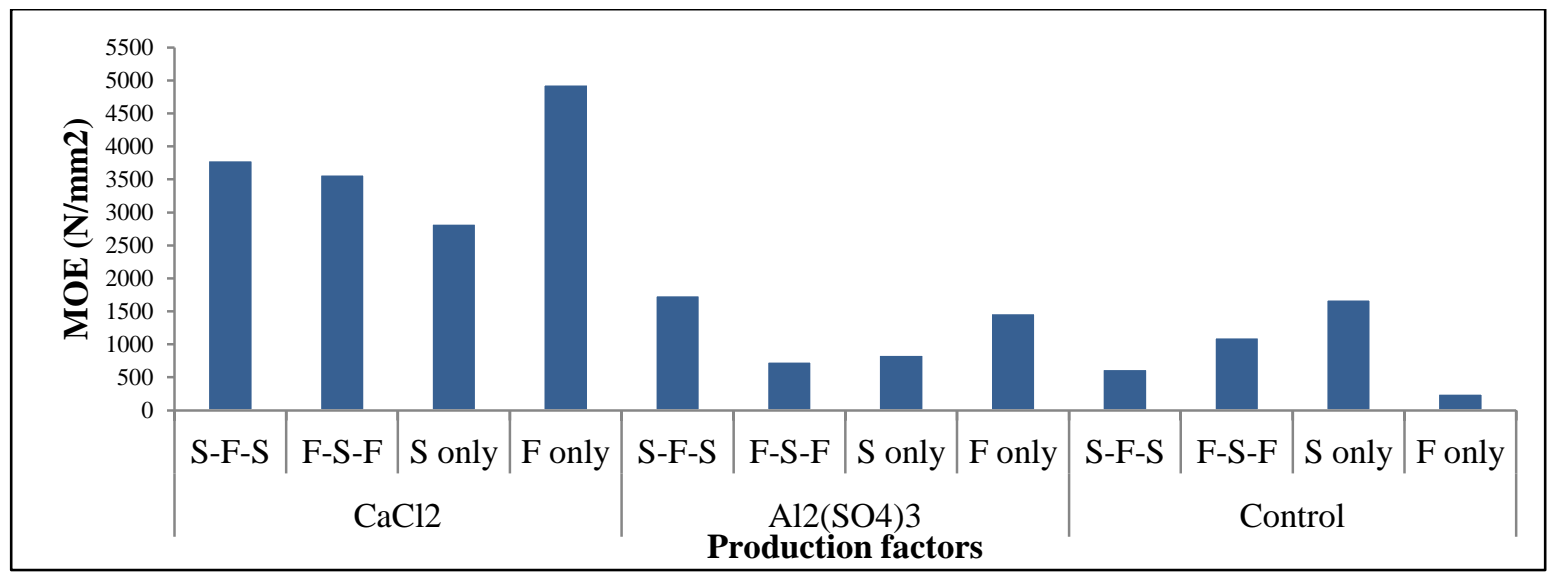

Figure 6: Effect of different treatment and fibre geometry on MOE of cement-bonded particle boards.

\subsection{Results of analysis of variance}

The results of analysis of variance carried out on the effects of pre-treatment, fibre geometry and fibre stratification on cement-bonded particle boards were significant at $0.05 \%$ probability level (Table 2). This implies that pre-treatment chemical additives, fibre geometry and fibre stratification has impact on the water absorption, thickness swelling, modulus of rupture and modulus of elasticity of cement bonded particle boards. This result agrees with the work of Frybort et al. (2008) that particle geometry influences almost all properties of cement-bonded particle boards. Separation of means of the different pre-treatment and geometric particle sizes was carried out using Duncan Multiple Range Test as presented in Table 2. The effects of $\mathrm{CaCl}_{2}$ and $\mathrm{Al}_{2}\left(\mathrm{SO}_{4}\right)_{3}$ were not significantly different for water absorption and thickness swelling on cement-bonded particle boards. However, CBPBs pre-treated with $\mathrm{Al}_{2}\left(\mathrm{SO}_{4}\right)_{3}$ has the lowest values for water absorption and thickness swelling while CBPBs with no pre-treatment has the highest values for water absorption and thickness swelling. This implies that $\mathrm{Al}_{2}\left(\mathrm{SO}_{4}\right)_{3}$ is the best pre-treatment additives for CBPBs against water absorption and thickness swelling.

The mean values of the strength properties of $\mathrm{CBPBs}$ shows that MOR and MOE with $\mathrm{CaCl}_{2}$ treatment had the highest value while the lowest mean value for MOR and MOE was observed in CBPBs with no pre-treatment. Therefore, the best pre-treatment for CBPBs production is $\mathrm{CaCl}_{2}$. The results of the particle geometry/stratification presented in Table 2 shows that CBPBs produced with sawdust/fibre/sawdust particle geometry stratification had the highest mean value and were significantly different from other particle geometry/stratification.

Table 1: Analysis of variance on the physical and mechanical properties of CBPBs.

\begin{tabular}{lrllrr}
\hline \multirow{2}{*}{ Source of variation } & & \multicolumn{4}{c}{ Variance } \\
\cline { 3 - 6 } & df & WA & \multicolumn{1}{c}{ TS } & \multicolumn{1}{c}{ MOR } & \multicolumn{1}{c}{ MOE } \\
\hline Pre-treatment & 2 & $8.14^{*}$ & $1.85^{*}$ & $32.74^{*}$ & $23.74^{*}$ \\
Fibre geometry & 3 & $3.54^{*}$ & $1.59^{*}$ & $2.65^{*}$ & $0.31^{*}$ \\
Fibre stratification & 6 & $1.49^{*}$ & $0.92^{*}$ & $3.76^{*}$ & $1.49^{*}$ \\
Error & 36 & & & & \\
Total & 47 & & & & \\
\hline
\end{tabular}

*Significant at $0.05 \%$ probability level. 
Table 2: Results of DMRT on pre-treatment, particle geometry/stratification of CBPBs.

\begin{tabular}{lllll}
\hline Pre-treatment & WA & TS & MOR & MOE \\
\hline $\mathrm{CaCl}_{2}$ & $14.62^{\mathrm{a}}$ & $2.03^{\mathrm{a}}$ & $8.79^{\mathrm{b}}$ & $3787.60^{\mathrm{b}}$ \\
$\mathrm{Al}_{2}\left(\mathrm{SO}_{4}\right)_{3}$ & $12.76^{\mathrm{a}}$ & $0.67^{\mathrm{a}}$ & $4.19^{\mathrm{a}}$ & $1202.00^{\mathrm{a}}$ \\
No-treatment & $24.94^{\mathrm{b}}$ & $5.58^{\mathrm{a}}$ & $3.83^{\mathrm{a}}$ & $919.95^{\mathrm{a}}$ \\
\hline Particle geometry/stratification & & & & \\
\hline Sawdust / fibre / Sawdust & $12.74^{\mathrm{a}}$ & $1.64^{\mathrm{a}}$ & $6.96^{\mathrm{b}}$ & $2057.60^{\mathrm{b}}$ \\
Fibre /sawdust fibre & $16.49^{\mathrm{b}}$ & $6.83^{\mathrm{b}}$ & $5.16^{\mathrm{a}}$ & $1810.50^{\mathrm{a}}$ \\
Sawdust only & $24.50^{\mathrm{c}}$ & $1.41^{\mathrm{a}}$ & $5.14^{\mathrm{a}}$ & $1788.30^{\mathrm{a}}$ \\
Fibre only & $16.01^{\mathrm{b}}$ & $1.45^{\mathrm{a}}$ & $5.14^{\mathrm{a}}$ & $2223.00^{\mathrm{b}}$ \\
\hline
\end{tabular}

Means in columns with the same superscript were not significantly different $(p>0.05)$

\section{Conclusion}

Cement-bonded particle boards were produced using different chemical pre-treatment, particle geometry and stratification. It was observed that Modulus of rupture (MOR) and Modulus of elasticity (MOE) were greater in the CBPBs produced using sawdust/fibre/sawdust stratification levels compared to CBPBs produced using other particle geometry/stratification levels. Thickness swelling (TS) was lowest in boards produced with sawdust only, this was followed by the sawdust/fibre/sawdust while water absorption (WA) was lower in the sawdust/fibre/sawdust stratification. Thus, sawdust/fibre/sawdust particle stratification on the average, produced boards of greater physical and mechanical properties.

Cement-bonded particle boards produced with pre-treatment were more dimensionally stable and has better strength properties than the untreated CBPBs. Pre-treatments increased the MOR and MOE values and reduced the WA and TS values for boards produced. Boards produced with the $\mathrm{CaCl}_{2}$ treatment additive had the greatest MOR and MOE values, while CBPBs produced with $\mathrm{Al}_{2}\left(\mathrm{SO}_{4}\right)_{3}$ had the least WA and TS values. Therefore, $\mathrm{CaCl}_{2}$ treatment additive increased the strength properties of CBPBs while $\mathrm{Al}_{2}\left(\mathrm{SO}_{4}\right)_{3}$ increase its resistance to water absorption and dimensional failure. Pretreatment, particle geometry and stratification has positive effect on the physical and mechanical properties of cement-bonded particle boards.

\section{References}

Ajayi, B. 2005. Cement-bonded particle boards manufactured from coffee chaff. Journal of Applied Tropical Agriculture, 10(1): 63-66.

Ajayi, B. 2011. Durability characteristic of cement-bonded particle boards form maize stalk residue. Journal of forestry research, 18(2): 73-89.

Amanda, S. and Untao, S. 2001. Fracture properties of Bamboo. Composites. Part B, 32: 451-459.

B.S D373 1989. British Standard Institution specification for wood chipboard and methods of test for particle board BS. 5669.

Frybort, S., Raimund, M., Alfred, T. and Muller, U. 2008. Cement bonded composites: A mechanical review, 3(2): 602-626.

Gills, L.S. and Onuga, J.E. 1989. A comparative study of the trachery elements of some commercial wood of Nigeria. Feddes Repertorium, 95: 645-655.

Morteza, N., Ebrahim, G. and Mohammed, D.G. 2011. The influence of wood extractives and additives on the hydration kinetics of cement paste and cement-bonded particle board. Journal of Applied Sciences, 11: 2186-2192. 
Papadopoulos, A.N. 2008. Natural Durability and performance of Hornbeam cement bonded particle board. Technological educational institute of Kavala, Branch of Drama, Department of Forestry and Management of Natural Environment, Laboratory of wood and wood products. TK 66100, Drama, Greece.

Wise, L.E., Murphy, M. And Addieco, A.A. 1946. Chloroite Holocellulose, its fractionation and bearing on summative wood analysis and on studies on the hemicellulose. Paper Trade Journal.122: 35-43.

$\mathrm{Xu}, \mathrm{Q}$. and Stark, J. 2005. Early hydration of ordinary Portland cement with an alkaline shotcrete accelerator. Advances in cement research, 17(1): 1-8.

Yu, Y., Fei, B.H., Wang, H.V. and Tian, G.L. 2011a. Longitudinal mechanical properties of cell wall of Masson Pine (Pinus massoniana lamb) as related to moisture content: A nanoindentation study. Holzforschung, 65(1): 121-126.

Yu, Y., Jiang, Z.H., Fei, B.H., Wang, G. and Wang, H.K. 2011b. An improved microtensile technique for mechanical characterisation of short plant fibre. A case study of Bamboo fibres. Journal of Natural Science, 46: 739-746. 